\title{
Colorectal cancers in a new mouse model of familial adenomatous polyposis: influence of genetic and environmental modifiers
}

\author{
Sabine Colnot ${ }^{1}$, Michiko Niwa-Kawakita ${ }^{2}$, Ghislaine Hamard ${ }^{3}$, Cécile Godard ${ }^{1}$, \\ Servane Le Plenier ${ }^{1}$, Christophe Houbron ${ }^{3}$, Béatrice Romagnolo ${ }^{1}$, Dominique Berrebi ${ }^{4}$, \\ Marco Giovannini ${ }^{2}$ and Christine Perret $^{1}$ \\ ${ }^{1}$ Departement Genetique, Developpement et Pathologie Moleculaire, Institut Cochin - INSERM, CNRS UMR \\ 8104, Universite Paris V, Paris, France; ${ }^{2}$ INSERM U434, Fondation Jean Dausset-CEPH, Paris, France; \\ ${ }^{3}$ Plateforme Recombinaison Homologue, Institut Cochin-INSERM 567, CNRS UMR 8104, Université Paris V, \\ Paris, France and ${ }^{4}$ Service d'Anatomie et de Cytologie Pathologiques, Hópital Robert Debré, Paris, France
}

\begin{abstract}
Murine models of familial adenomatous polyposis harbor a germinal heterozygous mutation on Apc tumor suppressor gene. They are valuable tools for studying intestinal carcinogenesis, as most human sporadic cancers contain inactivating mutations of $A P C$. However, $A_{p c^{+/-}}$mice, such as the well-characterized $A p c^{\mathrm{Min} /+}$ model, develop cancers principally in the small intestine, while humans develop mainly colorectal cancers. We used a Cre-loxP strategy to achieve a new model of germline Apc invalidation in which exon 14 is deleted. We compared the phenotype of these $A p c^{\Lambda 14 /+}$ mice to that of the classical $A p c^{\mathrm{Min} /+}$. The main phenotypic difference is the shift of the tumors in the distal colon and rectum, often associated with a rectal prolapse. Thus, the severity of the colorectal phenotype is partly due to the particular mutation $\Delta 14$, but also to environmental parameters, as mice raised in conventional conditions developed more colon cancers than those raised in pathogen-free conditions. All lesions, including early lesions, revealed Apc LOH and loss of Apc gene expression. They accumulated $\beta$-catenin, overexpressed the $\beta$-catenin target genes cyclin D1 and $c$-Myc, and the distribution pattern of glutamine synthetase, a $\beta$-catenin target gene recently identified in the liver, was mosaic in intestinal adenomas. The $A p c^{\Lambda 14 /+}$ model is thus a useful new tool for studies on the molecular mechanisms of colorectal tumorigenesis.
\end{abstract}

Laboratory Investigation (2004) 84, 1619-1630, advance online publication, 25 October 2004; doi:10.1038/labinvest.3700180

Keywords: colorectal cancer; $A p c ; \beta$-catenin; mouse model

Familial adenomatous polyposis (FAP) is an autosomal dominant disease in which many adenomatous polyps develop in the colon, and occasionally in the proximal gut, progressing to colorectal carcinoma. Genetic linkage studies have shown that inactivation of the adenomatous polyposis coli $(A P C)$ gene, located on chromosome $5 \mathrm{q} 21$, is responsible for the abnormalities in FAP. ${ }^{1,2}$ Therefore, inactivating $A P C$ is considered to initiate the multistep progression of colorectal cancer. ${ }^{3}$ Knowledge of how $A P C$ acts as a tumor suppressor gene was considerably advanced by the demonstration that APC contributes to the degradation of cytosolic $\beta$-catenin, linking APC to the Wnt/ $\beta$-catenin path-

Correspondence: Dr C Perret, PhD, Institut Cochin, GDPM, 24 Rue du Faubourg Saint Jacques, 75014 Paris, France.

E-mail: perret@cochin.inserm.fr

Received 13 April 2004; revised 23 July 2004; accepted 3 August 2004; published online 25 October 2004 way as a negative regulator. ${ }^{4-7}$ Consequently, the inactivation of $A P C$ leads to a constitutive accumulation of $\beta$-catenin that triggers an aberrant activation of the Wnt pathway. $C-M y c$ and Cyclin D1 (CCND1) were the first major $\beta$-catenin target genes identified..$^{8,9}$ The list of target genes is still growing, and some of them may be implicated in the initiation and progression of intestinal cancer (www.stanford.edu/ rnusse/wntwindow.html).

The first murine model of FAP carrying an $A p c$ mutation was the multiple adenomas neoplasia (Min) model. These mice, $A p c^{\mathrm{Min} /+}$, are heterozygous for a germline Leu $\rightarrow$ Stop mutation in codon 850 of $A p c .{ }^{10}$ They produce a truncated Apc protein that lacks the Apc domain responsible for $\beta$-catenin degradation. Like FAP patients, $A p c^{\mathrm{Min} /+}$ mice on the C57BL/6 (B6) background develop numerous adenomatous polyps. All the tumors have lost the $A p c$ wild-type allele. But, in contrast to FAP patients that develop multiple adenomas in the 
colon, most $A p c^{\mathrm{Min} /+}$ adenomas are found in the small intestine. The other mouse $A p c$ models carrying different $A p c$ germline mutation also result in a high incidence of adenomas in the small intestine. ${ }^{11-13}$ The reason why the phenotypes of mice and men differ is presently unknown.

During the establishment of a conditional $A p c$ knockout mouse using the Cre-loxP strategy, we developed a new germline $\mathrm{Apc}^{+/-}$model in which Apc exon 14 was deleted. Deletion of exon 14 generated a frameshift mutation at AA580 that disrupted the $A p c$ gene. In this study, we characterized these $\mathrm{Apc}^{\Delta 14 /+}$ mice and compared the intestinal phenotype to the classical $A p c^{\mathrm{Min} /+}$. This report describes how these $A p c^{\Delta 14 /+}$ mice faithfully mimick human FAP disease by the severity of their colon tumorigenesis.

\section{Materials and methods}

\section{Generation of Apc ${ }^{3 l o x 14 /+}$ ES Cells}

A 14.5-kb Apc genomic clone encompassing exons 11-15 was isolated from a mouse 129/Ola genomic library. For construction of the $A p c$ targeting vector, a 8.5-kb BamHI-XmnI fragment was subcloned in a modified pBR322 vector containing a NaeI-KpnI polylinker from pBluescript KS II (Stratagene). To generate the $A p c^{310 \times 14 /+}$ ES cells, a 2.9-kb BamHI fragment containing a floxed PGKHprt mini-gene was inserted into the BamHI site $0.4 \mathrm{~kb}$ downstream of exon 14. A third loxP site was introduced into the EcoRV site $0.5-\mathrm{kb}$ upstream of exon 14 . The $A p c^{310 \times 14 /+}$ targeting fragment was electroporated into ES cells of the hypoxanthine/guanine phosphoribosyltransferase (Hprt)-deficient, 129/Ola-derived, HM-1 cell line and HAT-resistant cells were selected for 7 days as described..$^{14}$ By Southern blot analysis of ES cell clones, using probes $A$ and $B$ and EcoRI-digested DNA, we identified 19 homologous recombinants out of $80 \mathrm{HAT}^{\mathrm{R}}$ clones.

\section{Generation and Genotyping of $\mathrm{Apc}^{3 \mathrm{lox} 14 /+}$ Mutant Mice}

Germline chimera mice were generated by injection of 12-15 $A p c^{310 \times 14 /+}$ mutant ES cells into C57BL/6 blastocysts and crossed with $\mathrm{C} 57 \mathrm{BL} / 6$ mice to produce outbred heterozygous offspring. $A p c^{3 \text { lox14/+ }}$ male mice (Figure 1a) were then crossed with transgenic MeuCre40 female mice (C57BL/6 background), as previously described. ${ }^{15}$ The resulting $A p c^{\Delta 14 /+}$ pups (Figure 1a), carrying the deletion of both exon 14 and the hprt cassette, were then mated with C57BL/6 mice and analyzed at N6 backcross. The genotypes of all offspring were analyzed by PCR or Southern blot analysis on tail-tip DNA. The $A p c^{\Delta 14}$ allele was detected with primers Apc.Int13S: 5'-CTAGTACTTTTCAGACGTCATG-3' and Apc.Int14a: 5'-CAATATAATGAGCTCTGGGCC-3' yielding a 240-bp ( $A p C^{\Delta 14}$ allele) product.
Mice

All animal procedures reported in this paper were carried out in accordance with French government regulations (services vétérinaires de la Santé et de la Production Animale, Ministère de l'Agriculture). Mice were commonly housed in conventional conditions, and the mice housed under specific pathogen-free conditions were kept in the animal units of CDTA, Orléans, France. All mice had free access to standard diet (UAR, France) and water.

\section{Adenoma Scoring and Histopathological Analysis}

Mice were killed by cervical dislocation, and the number of polyps determined. The whole intestinal tract of each mouse was removed, rinsed gently in PBS using a syringe and opened lengthwise. The opened intestine was spread flat on wax using entomological pins, and fixed in $4 \%$ formaldehyde. All polyps were counted under a dissecting microscope at $\times 15$ magnification, always by the same investigator. The smallest adenomatous polyps identified were about $0.5 \mathrm{~mm}$ in diameter. The whole intestine was then rolled and embedded in paraffin for histological and immunocytochemical analysis, and laser microdissection. We followed recently published recommendations for histological typing of the tumors. ${ }^{16}$

\section{Immunohistochemistry}

Sections $(5 \mu \mathrm{m})$ were cut of the paraffin-embedded 'swiss rolls' and those sections were treated with $3 \%$ hydrogen peroxide and an avidin/biotin blocking kit (Vector laboratories). The antigens were retrieved by treating sections (except those for APC immunostaining) with citrate buffer $\mathrm{pH}=6$ in a microwave pressure cooker. The monoclonal primary antibodies used were directed against human $\beta$-catenin (1/500, clone 14, BD Transduction Laboratories), mouse glutamine synthetase (1/200, BD Transduction Laboratories), mouse cyclin D1 (1/50, Dako) and mouse c-Myc (1/50, N262, TEBU). The sections incubated with the mouse monoclonal primary antibody, were treated with the M.O.M ${ }^{\mathrm{TM}}$ kit (Vector Laboratories) and visualized with $\mathrm{DAB}$ substrate. Rabbit polyclonal antibodies were directed against mouse Ki67 (1/400, Novocastra) and against human C-terminal part of APC (1/250, C20, Santa Cruz Biotechnologies). Sections incubated with anti-APC antibody were then incubated with biotinylated anti-rabbit secondary antibody (1/300, Vector Laboratories), followed by catalyzed signal amplification using the Dako CSA kit. The Ki-67-stained sections were incubated with anti-rabbit secondary antibody (1/100, Vector Laboratories), followed by peroxidase-anti-peroxidase (PAP, 1/100, Dako) treatment and visualization with $\mathrm{DAB}$ as substrate. 
a

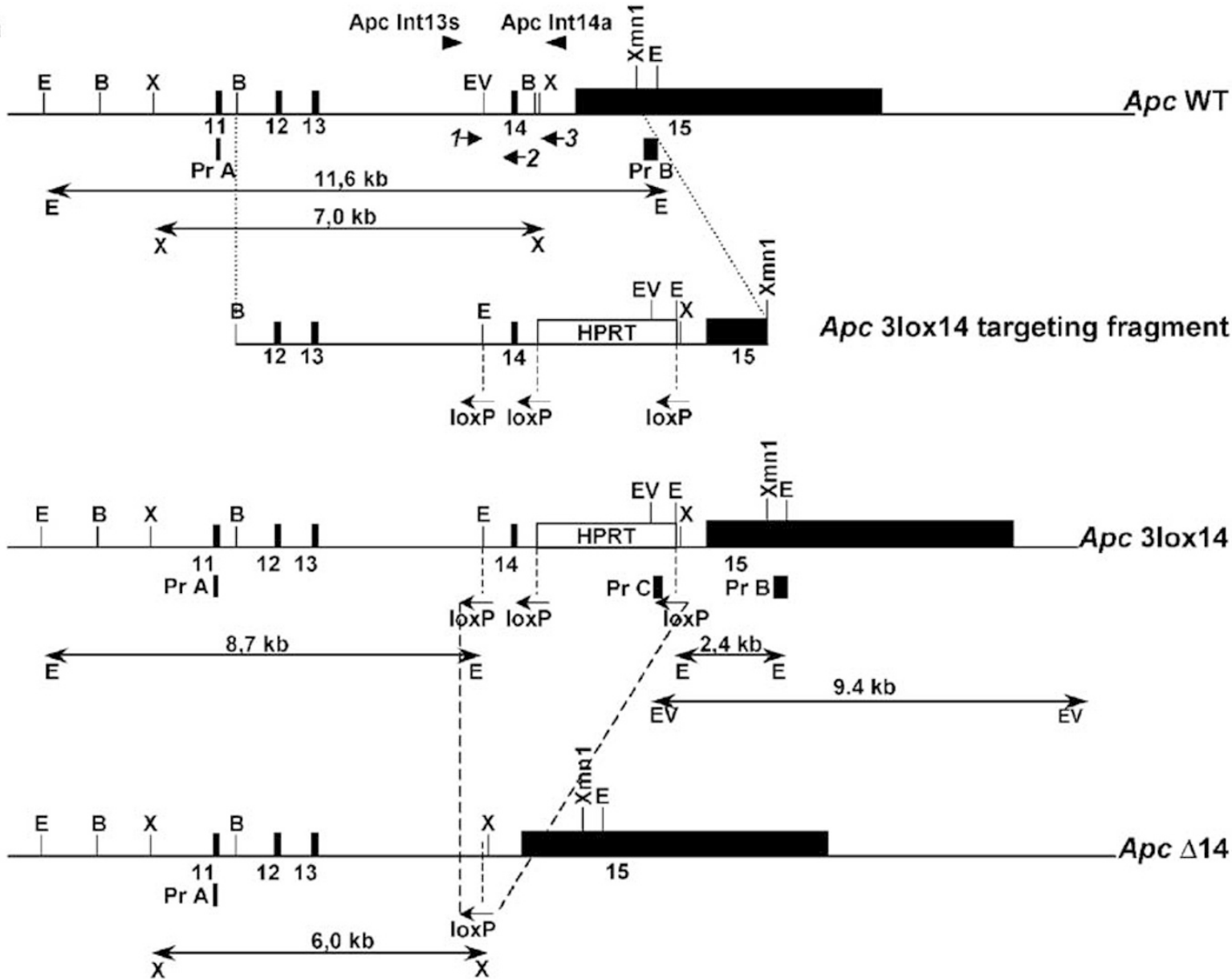

\section{b COLON DNA}

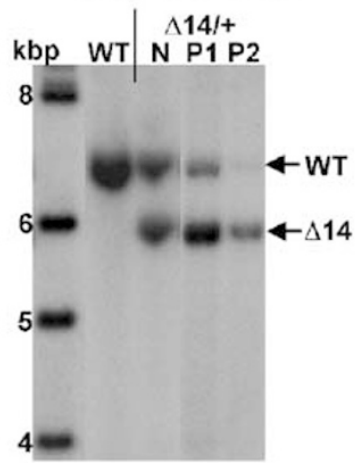

c COLON RNA

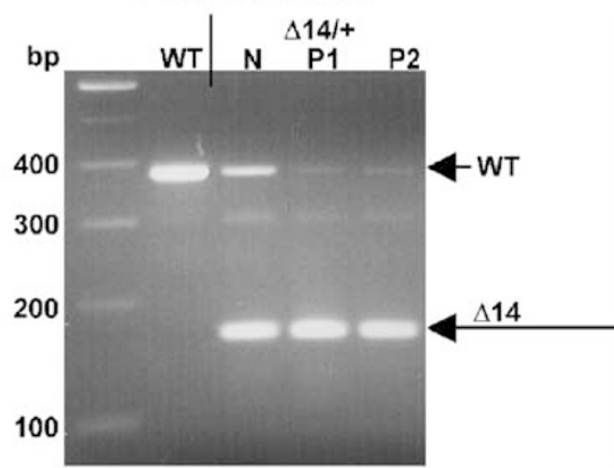

d

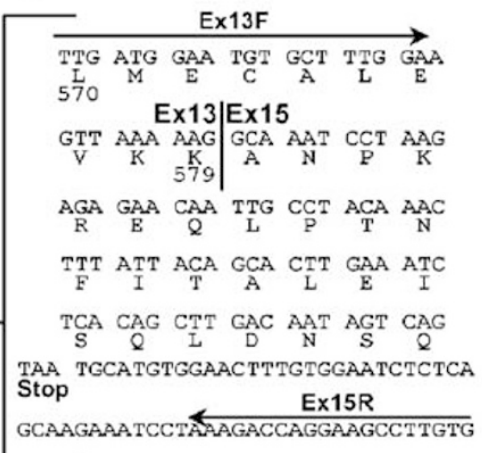

Figure 1 Generation of the $A p c^{\Delta 14}$ allele and analysis of $A p c$ inactivation in intestinal polyps. (a) Targeting strategy: restriction maps of the $A p c+$ allele ( $3^{\prime}$ portion), the $A p c^{3 l o x 14}$ targeting fragment, and the $A p c^{\Delta 14}$ allele after homologous recombination and Cre-mediated recombination. Exons 11-15 are indicated (black boxes), as are the restriction sites used for cloning and screening (B: BamHI, E: EcoRI, EV: EcoRV, X: XbaI). The $A p c^{3 l o x 14}$ targeting fragment comprises the floxed PGKHprt selection cassette, that was inserted into the BamHI site downstream of $A p c$ exon 14, plus a third loxP site that was introduced into the EcoRI site upstream of exon 14 . All $l o x P$ sites are indicated by arrows. In the first step of the strategy, the $A p c$ locus was targeted with the $A p c^{3 l o x 14}$ targeting fragment. In the second step, the PGKHprt selection cassette was removed by Cre recombinase that recombined the three loxP sites. The double-headed arrows indicate the DNA fragments resulting from digestions with different enzymes expected to hybridize with probes Pr A, Pr B or Pr C. Also depicted are the combinations of PCR primers that detect the $A p c^{\Delta 14}$ allele. (b-d) Inactivation of the wild-type $A p c$ allele in intestinal polyps. (b) LOH analysis: Southern blots of XbaI-digested colon DNAs, extracted from epithelium samples scraped from wild-type (WT) and $A p c^{\Delta 14 /+}$ mice $(\Delta 14 /+$, lane N), and from colon polyps (P1, P2), were hybridized with probe A (Pr A); first lane: DNA molecular weight ladder; the bands corresponding to the wild-type (WT) and the targeted ( $\Delta 14)$ alleles, are indicated with arrows. (c) Allele-specific RT-PCR analysis of the colon of wild-type mouse (WT), and normal epithelium (N) and polyps (P1, P2) from a $A p c^{\Delta 14 /+}$ mouse; first lane: DNA molecular weight ladder. (d) Sequence of the amplified targeted allele, showing the deletion of exon 14. 


\section{DNA Extraction and LOH Analysis}

DNA was extracted from macroscopic polyps and corresponding healthy tissue, and analyzed by Southern blotting after digestion with XbaI and hybridization with probe A surrounding the 11th exon of $A p c$. Early lesions were removed by microdissection with the $\mu$ CUT Laser Microdissection apparatus (Nikon, France) from 8- $\mu \mathrm{m}$ thick sections of paraffin-embedded 'swiss-rolls.' Genomic DNA was extracted from about 100 cells from these lesions or adjacent epithelium in a 50- $\mu$ l reaction (QiaAMP DNA minikit, Qiagen, France). PCR (40 cycles) was performed using $10 \mu \mathrm{l}$ of the DNA preparation and primers that distinguished the wild-type allele of $A p c$ from the exon 14-excised allele of $A p c$ (primer $1=5^{\prime}$-CTGTTCTGCAGTATGT TATCA; primer $2=5^{\prime}$-CTATGAGTCAACACAGGAT TA; primer $3=5^{\prime}$-TATAAGGGCTAACAGTCAATA).

\section{RNA Extraction and Analyses}

Total RNAs were extracted from frozen polyps or scraped epithelium by the guanidium thiocyanate single-step procedure.

Northern-blot analyses were performed with $15 \mu \mathrm{g}$ of total RNAs. Samples were electrophoresed through 1\% agarose-6\% formaldehyde gel. RNAs were transferred to Hybond $\mathrm{N}+$ membranes and hybridized with the corresponding ${ }^{32} \mathrm{P}$-labeled probes. The amounts of RNAs were confirmed to be equivalent by $18 \mathrm{~S}$ rRNA hybridisation.

Allele-specific RT-PCR analysis used reverse transcription by standard protocols (Invitrogen). RT-PCRs for Apc transcripts were done with Ex13F and Ex15R oligonucleotides (Figure 1d), 35 cycles of amplification with a hybridization temperature of $56^{\circ} \mathrm{C}$.

\section{Results}

$\mathrm{Apc}^{\mathrm{\Delta 14/+}}$ Mice Develop a More Severe Phenotype than Apc $^{\mathrm{Min} /+}$ Mice

A cohort of $A p c^{\Delta 14 /+}$ and $A p c^{\mathrm{Min} /+}$ mice raised in conventional housing was observed, and the survi- val analyzed over a period of 12 months. $A p c^{\Delta 14 /+}$ mice began to die at 4 months, with evident signs of rectal bleeding and anemia, and $50 \%$ of the mice were dead at 6 months. In contrast, $A p c^{\mathrm{Min} /+}$ mice, bred for two crosses with C57BL/6 mice, showed a better survival. $A p c^{\mathrm{Min} /+}$ mice began to die later, at 7 months old (Figure 2). Interestingly, rectal prolapses developed as early as 4 months in $A p c^{\Delta 14 /+}$ mice, involving $61 \%$ of the animals surviving to 6 months old (Figure 2 and Table 1), while this concerned only $28 \%$ of $A p c^{\mathrm{Min} /+}$ mice at 7 months old. Hence, $A p c^{\Delta 14 /+}$ mice have a more severe phenotype than $A p c^{\mathrm{Min} /+}$ mice.

We first counted polyps to determine whether altered survival and rectal prolapses were linked to more severe polyposis (Table 1). Conventionally housed mice showed no statistically significant difference in the total polyp counts of $A p c^{\Delta 14 /+}$ and $A p c^{\mathrm{Min} /+}$ mice. However, $24 \%$ of $A p c^{\Delta 14 /+}$ mice developed fewer than 10 polyps in the small intestine, while $A p c^{\mathrm{Min} /+}$ mice did not (Figure 3a). This phenomenon was reversed in the colon. All $A p c^{\Delta 14 /+}$ mice developed polyps in the distal colon, while $20 \%$ of the $A p c^{\mathrm{Min} /+}$ mice did not; $25 \%$ of $A p c^{\Delta 14 /+}$ mice developed more than 10 polyps, whereas no $A p c^{\mathrm{Min} /+}$ mice did (Figure 3b). When the polyposis in the colon was severe (more than 10

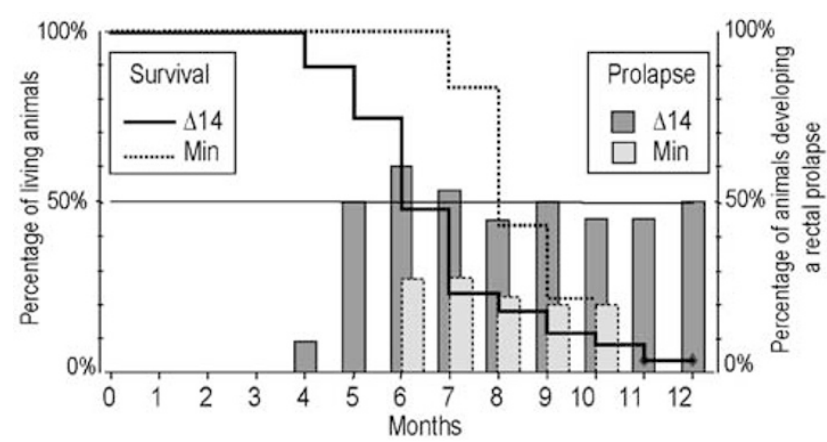

Figure 2 Time course of death and rectal prolapse in $A p c^{14 /+}$ and $A p c^{\mathrm{Min} /+}$ mice. Survival curves are in full $\left(A p c^{\Delta 14 /+}\right)$ or dashed $\left(A p c^{\mathrm{Min} /+}\right)$ lines. The percentages of living animals with a prolapsed rectum are shown as dark gray $\left(A p c^{\Delta 14 /+}\right)$ and light gray $\left(A p c^{\mathrm{Min} /+}\right)$ bars. Cohort numbers: $A p c^{\Delta 14 /+}, n=83 ; A p c^{\mathrm{Min} /+}$, $n=18, A p c^{\mathrm{Min} /+}$ mice were limited to a 10 -month follow-up.

Table 1 Tumorigenesis in $\mathrm{Apc}^{\Delta 14 /+}$ mice

\begin{tabular}{|c|c|c|c|c|}
\hline \multicolumn{2}{|c|}{ Housing conditions } & \multicolumn{2}{|c|}{ Conventional housing } & \multirow{2}{*}{$\frac{S P F}{\Delta 14}$} \\
\hline & line & Min & $\Delta 14$ & \\
\hline Extraintestinal phenotype & Mammary gland tumors ${ }^{\mathrm{a}}$ & $12 \%$ & $9 \%$ & $8 \%$ \\
\hline \multirow[t]{2}{*}{ Intestinal phenotype } & Number of polyps ${ }^{\mathrm{b}}$ & $34 \pm 18$ & $36 \pm 29^{*}$ & $65 \pm 23^{*}$ \\
\hline & Rectal prolapse $^{\mathrm{a}}$ & $28 \%$ & $61 \%$ & $15 \%$ \\
\hline
\end{tabular}

${ }^{\mathrm{a}}$ Macroscopical observations made on living animals: $n=18$ for $\mathrm{Apc}^{\mathrm{Min} /+}$ mice, $n=83$ and 23 for conventional housing and SPF Apc ${ }^{\Delta 14 /+}$ mice, respectively.

${ }^{\mathrm{b}}$ Mice were killed at the mean age of apparition of intestinal bleeding and anemia: about 180 days for the Apc ${ }^{\text {Min/+ }}$ mice $(n=6)$, 150 days for the $\mathrm{Apc}^{\Delta 14 /+}$ mice in conventional housing $(n=19), 120$ days for the SPF Apc ${ }^{\Delta 14 /+}$ mice $(n=8)$.

${ }^{*} P<0.05$ by Student's $t$-test. 


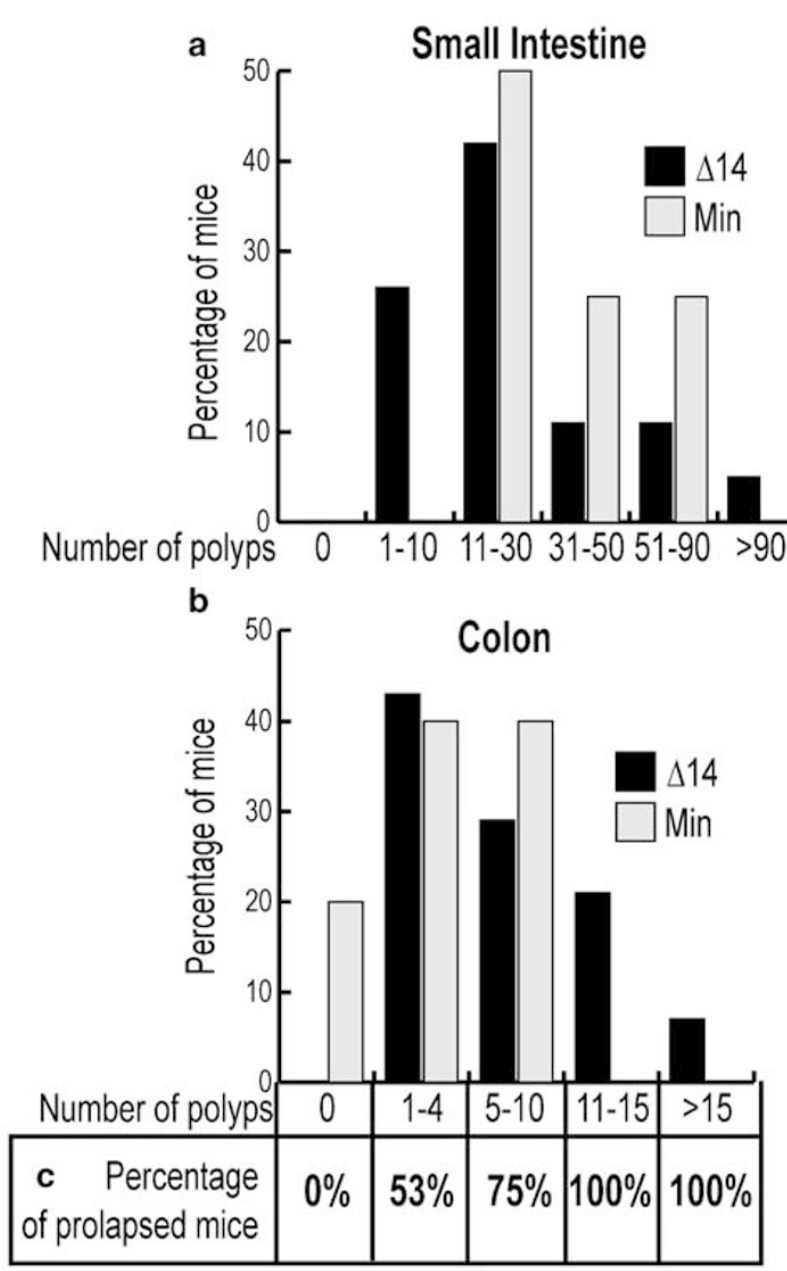

Figure 3 Numbers of polyps in $A p c^{\Delta 14 /+} v s A p c^{\mathrm{Min} /+}$ mice. The distributions are expressed as the percentages of mice (black bars for $A p c^{\Delta 14 /+}(\Delta 14)$; gray bars for $A p c^{\mathrm{Min} /+}$ (Min)) having 0, 1-10 polyps (1-10), 11-30 polyps (11-30), 31-50 polyps (31-50), 51-90 polyps (51-90) or more than 90 polyps (>90), in (a) the small intestine, (b) the colon. (c) percentage of mice having a prolapsed rectum in each polyp number category. Cohort numbers: $A p c^{\Delta 14 /+}, n=22$, killed at 140-160 days old; $A p c^{\mathrm{Min} /+}, n=11$, killed at 170-200 days old.

polyps per mouse), it was always associated with a rectal prolapse (Figure 3c), showing that the rectal prolapse is associated with the severity of the colorectal carcinogenesis. Altogether these results showed that compared to the $A p c^{\mathrm{Min} /+}$ mice, $A p c^{\Delta 14 /+}$ mice revealed a shift in the distribution in the tumors that are more frequent in the distal colon and rectum in the latter.

The $A p c^{\Delta 14 /+}$ mice, like $A p c^{\mathrm{Min} /+}$ mice, developed extraintestinal lesions such as mammary gland tumors (Table 1). Histological analysis of four of them (two $A p c^{\Delta 14 /+}$ mice and two $A p c^{\mathrm{Min} /+}$ mice) showed that these tumors were mammary adenoacanthomas (data not shown), in agreement with a previous report. ${ }^{13}$ Furthermore, homozygosity for the $A p c^{\Delta 14}$ mutation was not compatible with adult life. $A p c^{\Delta 14 /+}$ males were mated with $A p c^{\Delta 14 /+}$ females and the DNA from 46 newborn pups was examined for $A p c$ status: $63 \%$ were heterozygous while $37 \%$ were wild-type, and no pups had the $A p c^{\Delta 14 / \Delta 14}$ genotype. Thus, homozygous deletion of exon 14 of $A p c$ is embryonically lethal, as it is in other $A p c \mathrm{KO}$ mouse models.

\section{Histologic Analysis of Intestinal Polyps}

The 'swiss-rolls' enabled us to analyze the whole intestine. $\beta$-Catenin immunostaining was used to reveal all the dysplastic figures. A dark-brown staining marks the accumulation of the protein in the cytoplasm and the nucleus, and that is the hallmark of the activation of Wnt signalling in intestinal tumors. ${ }^{4,5}$ Intestinal lesions developed in the $A p c^{\Delta 14 /+}$ mice were distributed all along the intestine (Figure 4a). The histology of the lesions was compared in $A p c^{\Delta 14 /+}$ and in $A p c^{\mathrm{Min} /+}$ mice and standard optic microscopy did not reveal any qualitative changes. Hematoxylin- and eosin (H\&E)stained sections revealed small and large adenomas, in situ carcinomas, that had developed in both the small and the large intestines (Figure 4a, d and f). Tubular adenomas harboring invasive carcinomas were only present in animals over 12 months old, represented $50 \%$ of their lesions (Figure $4 \mathrm{e}$ ) and invaded the muscularis propria. No hepatic metastasis were seen in the four 12-month-old mice examined. Finally, early lesions were frequent in the small intestine of both $A p c^{\Delta 14 /+}$ and $A p c^{\mathrm{Min} /+}$ mice (Figure 4b), and ACF (aberrant crypt foci) were seen in the colon (Figure 4c).

Analysis of a longitudinal section of a prolapsed distal colon showed that the colon was filled with obstructing polyps (Figure 4f). The prolapses themselves were highly dysplastic with a distortion of the glands, the external part of the epithelium being ulcerated (Figure 4f). Adenocarcinoma invasive into the muscularis propria was seen in $10 \%$ of the dysplastic areas (Figure 4g). As rectal prolapses are often described in mouse models of inflammatory bowel disease (IBD), ${ }^{17,18}$ we asked whether inflammation did occur in $A p c^{\Delta 14 /+}$ prolapses. Indeed, inflammatory cells were present in the stromal component of both the dysplastic areas in the rectal prolapse, and every polyp (Figure 4d), but were strictly restricted to these regions. Globally, these anomalies did not affect the whole distal colon (data not shown), and therefore did not represent a full convincing pattern of IBD, such as that graded in IL-10-/- studies: ${ }^{19}$ particularly, no crypt abcess and no transmural inflammatory infiltrate could be observed.

Thus, $A p c^{\Delta 14 /+}$ mice bore a number of histological lesions from early lesions involving only one crypt to invasive carcinomas. The presence of numerous colonic carcinomas, probably associated with colon obstruction, could be the cause of the increased lethality of $A p c^{\Delta 14 /+}$ model. 


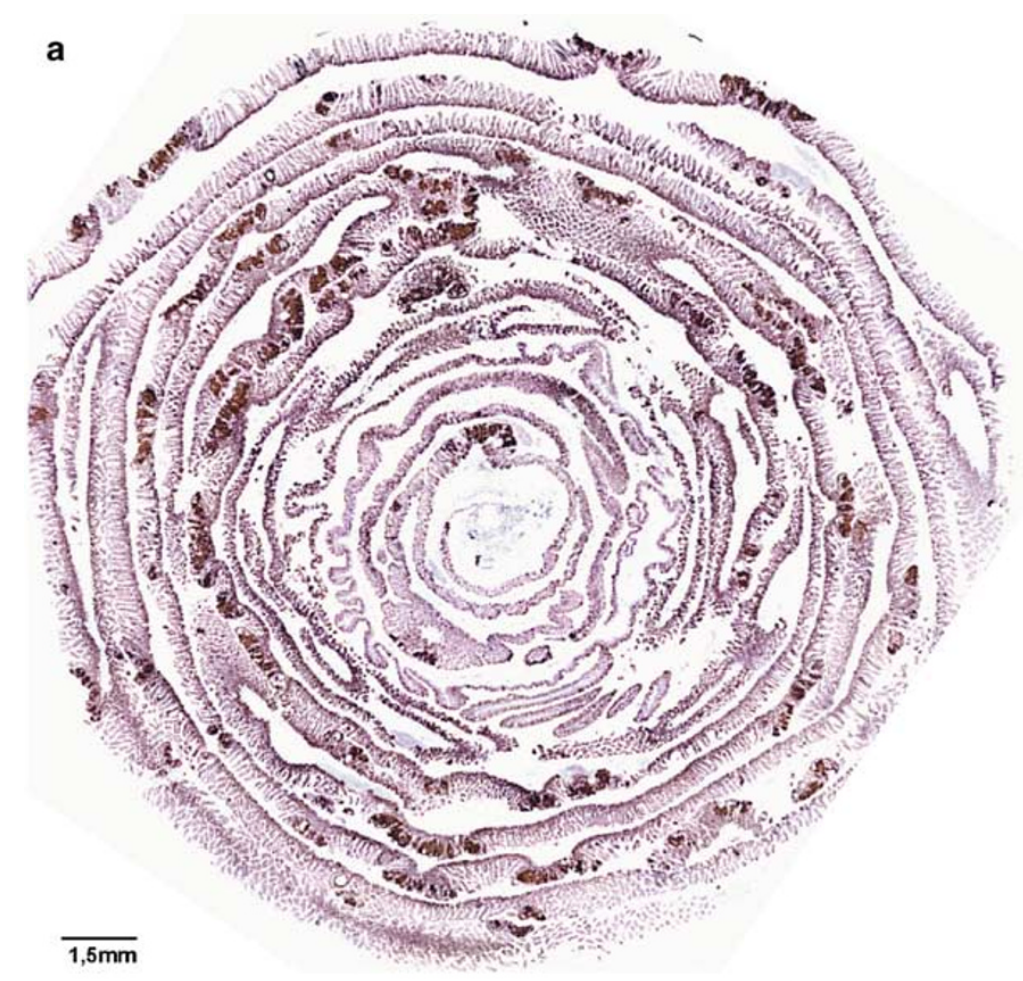

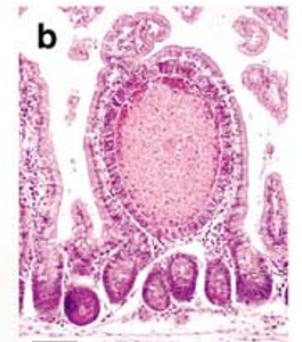
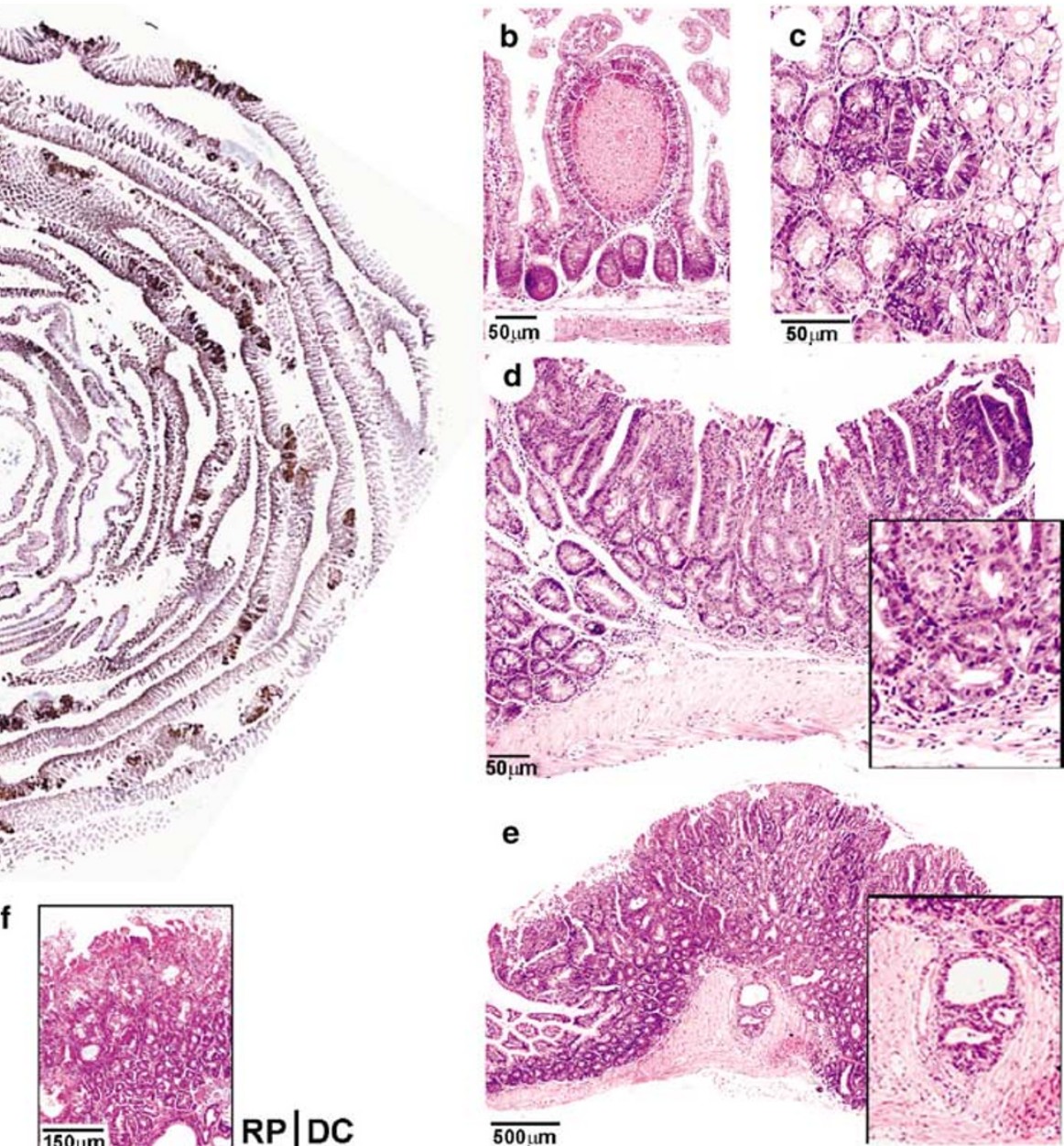

$500 \mathrm{um}$
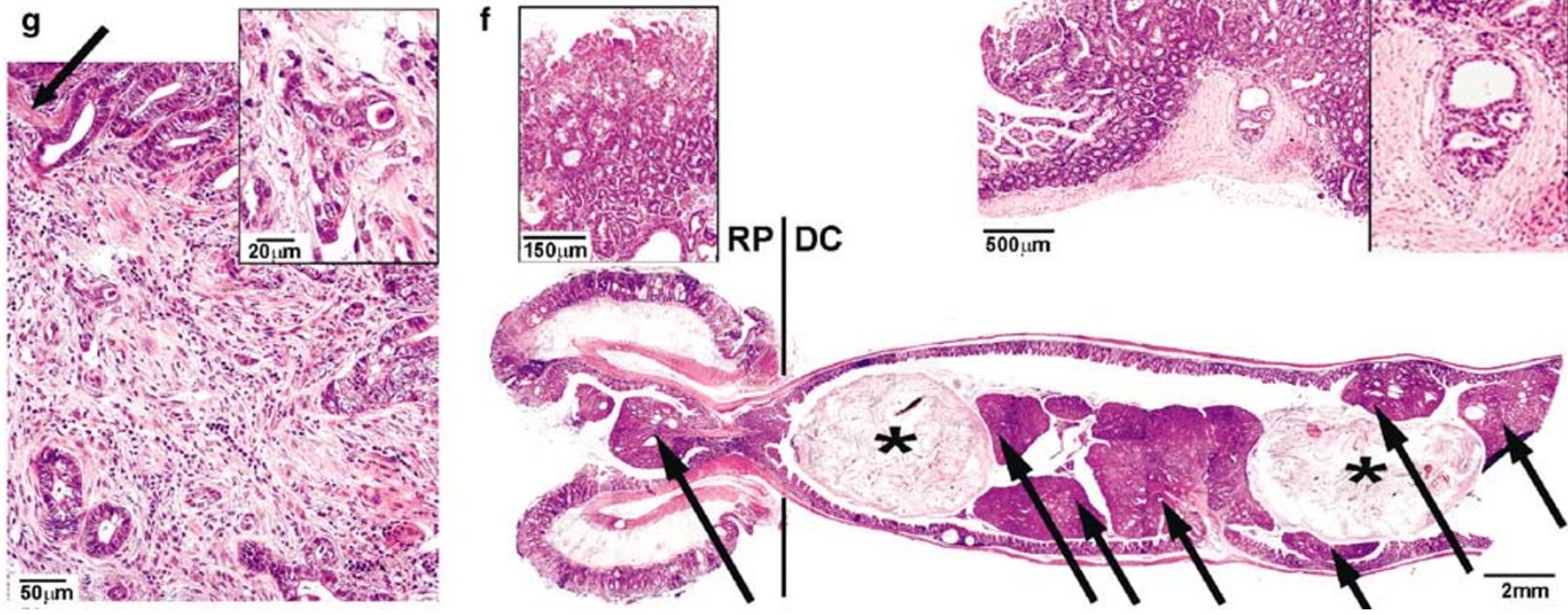

Figure 4 Histology of the dysplastic lesions in $A p c^{14 /+}$ mice. (a) $\beta$-Catenin immunostaining of a whole intestine swiss-roll from a 5month-old $A p c^{\Delta 14 /+}$ mouse. The small intestine is located on the external part of the swiss-roll, while the colon is in the center. The darkbrown staining indicates the accumulation of $\beta$-catenin in all dysplastic lesions. More than 90 lesions were present in the small intestine, and there were three lesions in the colon. Hematoxylin-eosin staining (b-g) of swiss-rolls of a 5-month-old mouse (b-d) and a 13-monthold mouse (e). (b) Early dysplastic lesion of the small intestine consisting of a single dysplastic crypt within a normal villus; this dysplastic crypt is filled with necrotic material. (c) Aberrant crypt foci in the colon. (d) Tubular adenoma of the small intestine, in lowgrade dysplasia: some inflammatory cells can be seen in the chorion (inset). (e) Well-differentiated adenocarcinoma in the small intestine: the inset shows the invasion of malignant glands into the submucosa. (f) Longitudinal section of the last $3 \mathrm{~cm}$ of the distal colon (DC) and the adjacent extruded rectal prolapse (RP) of a 5-month-old mouse: the distal colon is filled with feces (asterisks) and seven colon in situ carcinomas (arrows); the surface epithelium of the rectal prolapse is highly dysplastic and ulcerated (inset) and a polyp is extruded (arrow). (g) Enlargement of the rectal prolapse revealing an invasive carcinoma with desmoplasia and some inflammatory cells, irregular glands and loss of mucosal lining in invading glands (inset); the muscularis mucosa is pointed by an arrow.

\section{Influence of the Housing Conditions on the Development of the Intestinal Phenotype}

We wondered whether the severity of colorectal polyposis in $A p c^{\Delta 14 /+}$ mice was linked to housing conditions. Fewer $A p c^{\Delta 14 /+}$ mice raised under specific pathogen-free (SPF) conditions developed a rectal prolapse than did those raised in conventional conditions (Table 1). However, the polyp counts showed a statistically significant increased 
polyposis under SPF conditions (Table 1). The distributions of the polyps under the two housing conditions were completely different: $70 \%$ of the SPF-housed $A p c^{\Delta 14 /+}$ mice (analyzed at 120 days old) developed more than 50 polyps (Figure 5a, compared to $14 \%$ in conventional conditions), with $90 \%$ of them in the ileum, while conventionalhoused $A p c^{\Delta 14 /+}$ mice (analyzed at 150 days old) had polyps scattered along the whole small intestine; $29 \%$ of the SPF $A p c^{\Delta 14 /+}$ mice did not develop any polyps in the colon (Figure $5 \mathrm{~b}$ ), associated with fewer cases of rectal prolapses (Table 1). Thus, the conventional housing conditions favor the development of colorectal polyposis in $A p c^{\Delta 14 /+}$ mice, while a pathogen-free environment favors ileal polyposis in these $\mathrm{ApC}^{+/-}$mice. No evidence for the primary involvement of a contagious pathogen was found by PCR or microbiological analyses compared in both environments, which were negative for Helicobacter species, hepaticus, Citrobacter rodentium, Clostridium difficile, Campylobacterium, Salmonella, Yersinia. Moreover, a similar presence of inflammatory

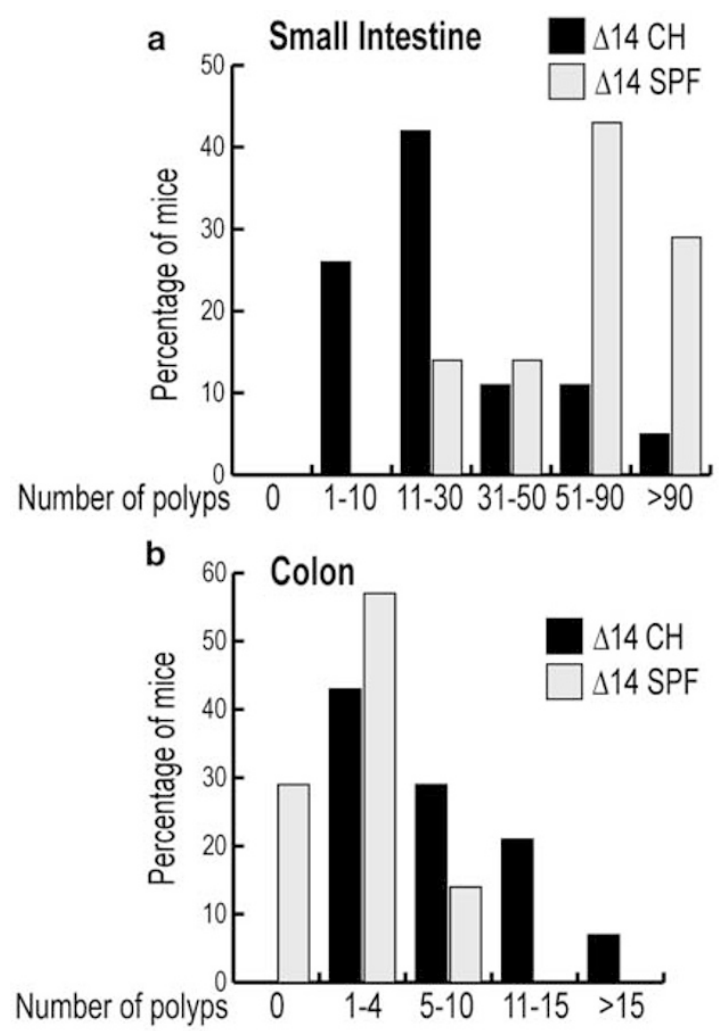

Figure 5 Numbers of polyps in $A p c^{\Delta 14 /+}$ mice bred in conventional housing and in specific pathogen-free housing. The distributions are expressed as the percentage of mice (black bars for $A p c^{\Delta 14 /+}$ in conventional housing $(\Delta 14 \mathrm{CH})$; gray bars for $A p c^{\Delta 14 /+}$ in SPF housing ( $\left.\Delta 14 \mathrm{SPF}\right)$ ) having $0,1-10$ polyps (1-10), 11-30 polyps (11-30), 31-50 polyps (31-50), 51-90 polyps (5190) or more than 90 polyps $(>90)$, in (a) the small intestine, (b) the colon. Cohort numbers: $A p c^{\Delta 14 /+}$ conventional, $n=22$, killed at 140-160 days old; $A p c^{\Delta 14 /+} \mathrm{SPF}, n=13$, killed at 110-140 days old. cells in the stroma of the polyps was seen in both conditions (data not shown).

Our results therefore show that the distribution of the polyps in $\mathrm{ApC}^{+/-}$mice is greatly influenced by at least two factors: an endogenous genetic factor, which is the location of the mutation on the $A p c$ gene $\left(A p c^{\Delta 14 /+} v s A p c^{\mathrm{Min} /+}\right.$ mice), and an exogenous factor linked to as yet unidentified environmental parameters in which the mice are raised.

\section{Molecular Analysis of Intestinal Polyps}

$\mathrm{LOH}$ analyses were done on the $A p c$ gene to investigate the molecular mechanisms of polyp formation in $A p c^{\Delta 14 /+}$ mice. LOH analysis of XbaIdigested intestinal DNA showed that the normal epithelium of $A p c^{\Delta 14 /+}$ mice harbored both the targeted and the wild-type allele of $A p c$ (Figure 1a and $b$ ). All the intestinal polyps analyzed (12 from the small intestine and 14 from the colon) showed a significantly less intense wild-type allele of $A p c$ band; it was partially or completely lost (P1 and P2 colonic polyps in Figure 1b). The weak persistence of the wild-type allele was probably due to nontumor cells. Therefore, Apc LOH occurred in all the polyps of $A p c^{\Delta 14 /+}$ mice, as in the other Apc KO mouse models.

Inactivation of the wild-type $A p c$ allele was confirmed by $A p c$ allele-specific RT-PCR analysis. Two mRNA species were amplified from the normal intestine of $A p c^{\Delta 14 /+}$ mice: a $400 \mathrm{bp}$ product from the WT allele, and a shorter $180 \mathrm{bp}$ product from the targeted allele (Figure 1c). Whereas the amount of the shorter transcript remained unchanged in the normal intestine and polyps, there was significantly less WT mRNA in the polyps, indicating the inactivation of the WT Apc allele (Figure 1c). The sequence of the $180 \mathrm{bp}$ product confirmed the deletion of exon 14 from the targeted allele that results in a frameshift mutation at codon 580, leading to a premature stop codon (Figure 1d). This inactivation of $A p c$ led to the aberrant immunolocalization of $\beta$-catenin: normal villi had only membrane staining for $\beta$-catenin, while all the dysplastic lesions (early lesions as well as adenoma and carcinoma) had high concentrations of the protein in the cytoplasm (Figures 4a, 6b). The extruded part of the prolapsed rectum was also immunostained for $\beta$-catenin. Both the ulcerated external epithelium and the invaginated dysplastic crypts stained strongly for $\beta$-catenin in the cytoplasm (Figure 6c). The intensity of the $\beta$-catenin accumulation was strictly correlated with increased cell proliferation, as shown by KI67 staining (Figure 6d).

We analyzed the expression of known targets of this pathway, c-Myc and cyclin D1, so as to evaluate the suitability of the $A p c^{\Delta 14 /+}$ model for searching for new $\beta$-catenin target genes implicated in intestinal carcinogenesis. There was a strict correla- 
tion between the accumulation of $\beta$-catenin in the polyps and overexpression of c-Myc and cyclin D1 (Figure 6e-g). Thus, the mRNAs encoding cyclin D1 and c-Myc are more abundant in the polyps and in the prolapsed rectums than in the normal epithelium (Figure 6i), confirming that c-Myc and cyclin D1 are $\beta$-catenin targets in the intestine in vivo.

We also analyzed expression of a $\beta$-catenin target gene that we have recently isolated from the liver, the glutamine synthetase gene. ${ }^{20}$ The glutamine synthetase gene is mainly expressed in the colon of wild-type mice (Figure 6h). The amount of GS in most epithelial cells of the colon polyps developed in $A p c^{\Delta 14 /+}$ mice is subnormal (Figure 6h). However, there is a mosaïc overexpression of GS, with patches of intensely GS-stained cells within the polyp. There is no GS in normal small intestine villi, but the polyps also overexpress GS in a mosaic pattern (data not shown). There was no clear correlation between the amounts of cytosolic $\beta$-catenin and GS in the intestinal polyps, in contrast to c-Myc and cyclin D1. Thus, the control of GS synthesis by $\beta$ catenin in the intestine appears to be more complex than in the liver.

\section{Molecular Analysis of Early Lesions}

In $A p c^{\Delta 14 /+}$ mice, colonic ACF accumulated $\beta$ catenin in the cytosol (data not shown), as it is the case in the BCAC ( $\beta$-catenin accumulated crypts) described in AOM-treated rats. ${ }^{21}$ However these ACF were unfrequent in $A p c^{\Delta 14 /+}$ mice, and it is the reason why we chose to study the numerous early lesions present in the small intestine.

Early lesions were described by Taketo's group in 1997, and more recently by Clevers' group in $2003{ }^{22,23}$ We performed genomic PCR analysis and Apc immunolocalization to confirm that $A p c \mathrm{LOH}$ occurs in these lesions. Immunostaining with an antibody directed against the C-terminal part of APC confirmed the location of Apc in the villi and not in the crypts in normal small intestine (Figure 7a). By contrast, there was no Apc in any of the early lesions analyzed (Figure 7a). Neither was there Apc in any of the polyps. Genomic PCR analysis on lasermicrodissected early lesions (Figure $7 \mathrm{~b}$ ) showed that the ratio between the band intensities of the wild-type and targeted alleles was significantly reduced in all the early lesions analyzed, indicating Apc LOH.

Thus, $A p c$ inactivation leads to the accumulation of $\beta$-catenin in the cytosol and nucleus in these early lesions, and overproduction of cyclin D1 and $\mathrm{c}-\mathrm{Myc}$ in the nuclei (Figure $7 \mathrm{c}-\mathrm{e}$ ). But the liver $\beta$-catenin target gene, glutamine synthetase, was not induced in the early lesions examined, supporting the fact that the control of transcription by $\beta$-catenin depends on the cellular context (Figure $7 \mathrm{f}$ ).

\section{Discussion}

We have developed a new FAP mouse model, in which a germline targeted heterozygous deletion of $A p c$ exon 14 leads to severe colon polyposis. The severity of the phenotype depends on how the mice are housed, suggesting that the microenvironment is an important factor for the development of intestinal polyps.

The degree of polyposis suffered by FAP patients varies, apparently because of the position of the $A p c$ mutation. But there is also great variability between individuals, probably linked to genetic modifiers and/or environmental factors. ${ }^{24}$ The same genetic variation occurs in $A p C^{+/-}$mouse models, as $A p c$ mutated alleles have been obtained on codon $1638(A p c 1638 \mathrm{~N})$, codon $716\left(A p c^{\Delta 716}\right)$, codon 850 $\left(A p c^{\mathrm{Min}}\right)$, codon $474\left(A p c^{\Delta 474}\right)$, and codon 580 $\left(A p c^{\Delta 14}\right)$. Apc1638N mice have an attenuated phenotype, ${ }^{12}$ like FAP patients harboring a mutation on the $3^{\prime}$ end of human APC. ${ }^{25}$ The mutations in the four other $A p c$ mouse models are relatively close together, between codons 580 and 850. Despite this, their phenotypes differ: $A p c^{\Delta 716 /+}$ mice have many polyps (more than 300 per mouse), while $A p c^{\mathrm{Min} /+}$, $A p c^{\Delta 14 /+}$ and $A p c^{\Delta 474 /+}$ mice have only $30-100$ polyps. ${ }^{10,11,13}$ However, the $A p c^{\Delta 716}$ allele still contains the recombination selection cassette that could interfere with the transcription of the targeted allele. And the recombination that produced the $A p c^{\Delta 474}$ allele leads to the duplication of exons 7-10 in the targeted allele. As a consequence, only $A p c^{\mathrm{Min} /+}$ and $A p c^{\Delta 14 /+}$ mice harbor a clean $A p c$ mutation, and can be compared to each other.

Figure 6 Molecular analysis of the lesions developed in $A p c^{\Delta 14 /+}$ mice. Small intestine normal epithelium (a) and intestinal lesions $(\mathbf{b}, \mathbf{c}, \mathbf{e})$ : small intestine adenoma (b), colon adenoma (e), dysplastic areas of the rectal prolapse (c) were immunostained for $\beta$-catenin. (a) $\beta$-catenin membranous staining in enterocytes in the normal villous; (b,e) heavy cytosolic and nuclear immunostaining for $\beta$-catenin in dysplastic enterocytes, unlike the membranous staining of the normal epithelium surrounding the adenoma; (c, d) immunostaining for $\beta$ catenin and Ki-67 on serial sections: cytosolic $\beta$-catenin and nuclear Ki67 staining colocalize in the dysplastic and ulcerated surface epithelium of the rectal prolapse. Note the Ki67 staining in the proliferative compartment at the bottom of the colon crypts. (f-h) Immunostaining of $\beta$-catenin target genes on serial sections of colon adenomas: (f) cyclin D1, (g) c-Myc, (h) glutamine synthetase. Dysplastic cells that accumulate $\beta$-catenin also overexpress cyclin D1, and c-Myc in their nuclei. (h) Normal crypts of the colon contain glutamine synthetase, but there is very little in dysplastic crypts. Only a few dysplastic cells stain strongly for GS. (i) Northern blots for cyclin D1 and c-Myc in four normal colon mucosae (N1, N2, N3, N4), four colon polyps (P1, P2, P3, P4), and three rectal prolapses (RP1, RP2, RP3). 

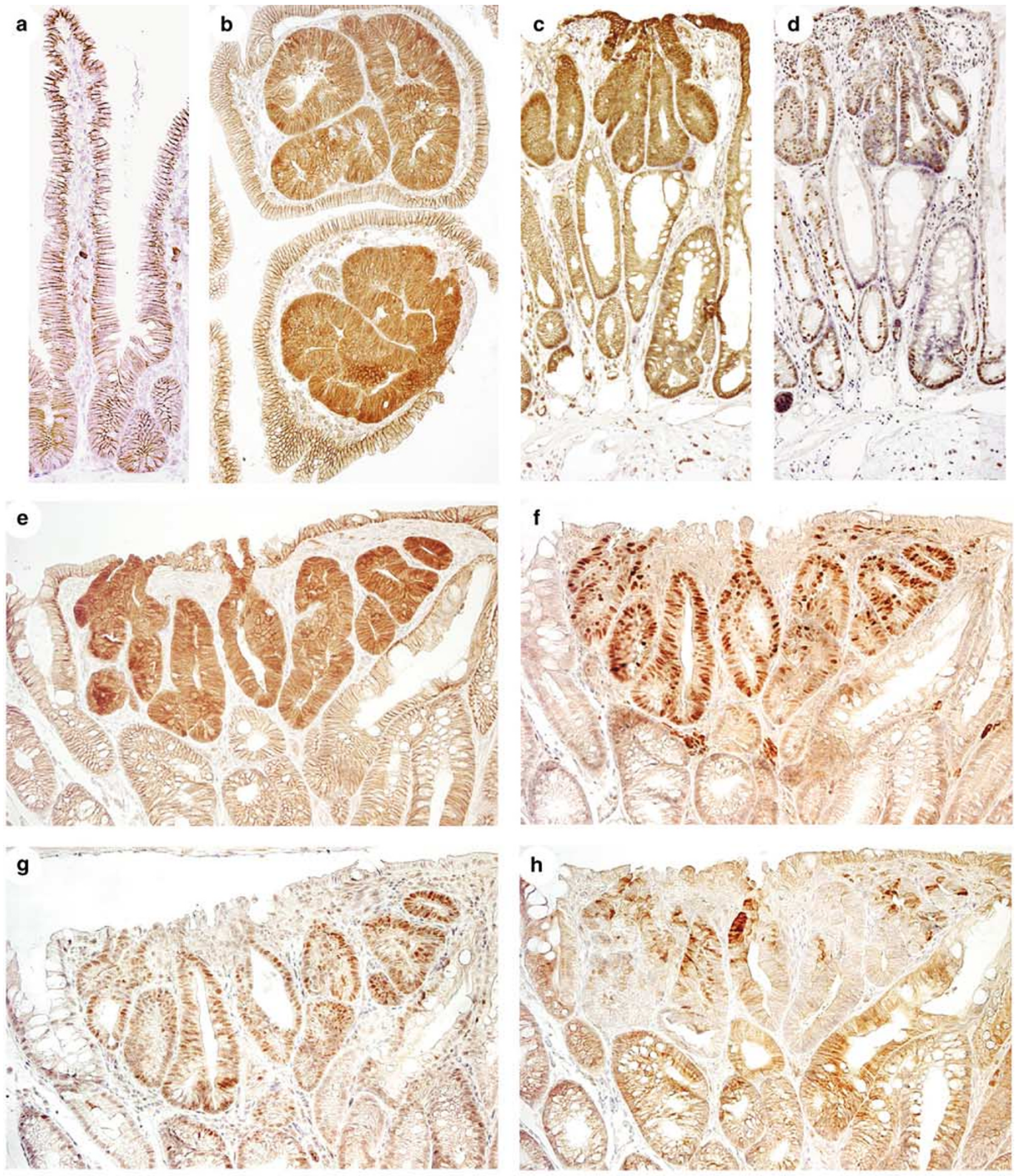

$\begin{array}{lllllllllll}\text { N1 } & \text { N2 } & \text { N3 } & \text { N4 } & \text { P1 } & \text { P2 } & \text { P3 } & \text { P4 } & \text { RP1 } & \text { RP2 } & \text { RP3 }\end{array}$

Cyclin D1

c-Myc 

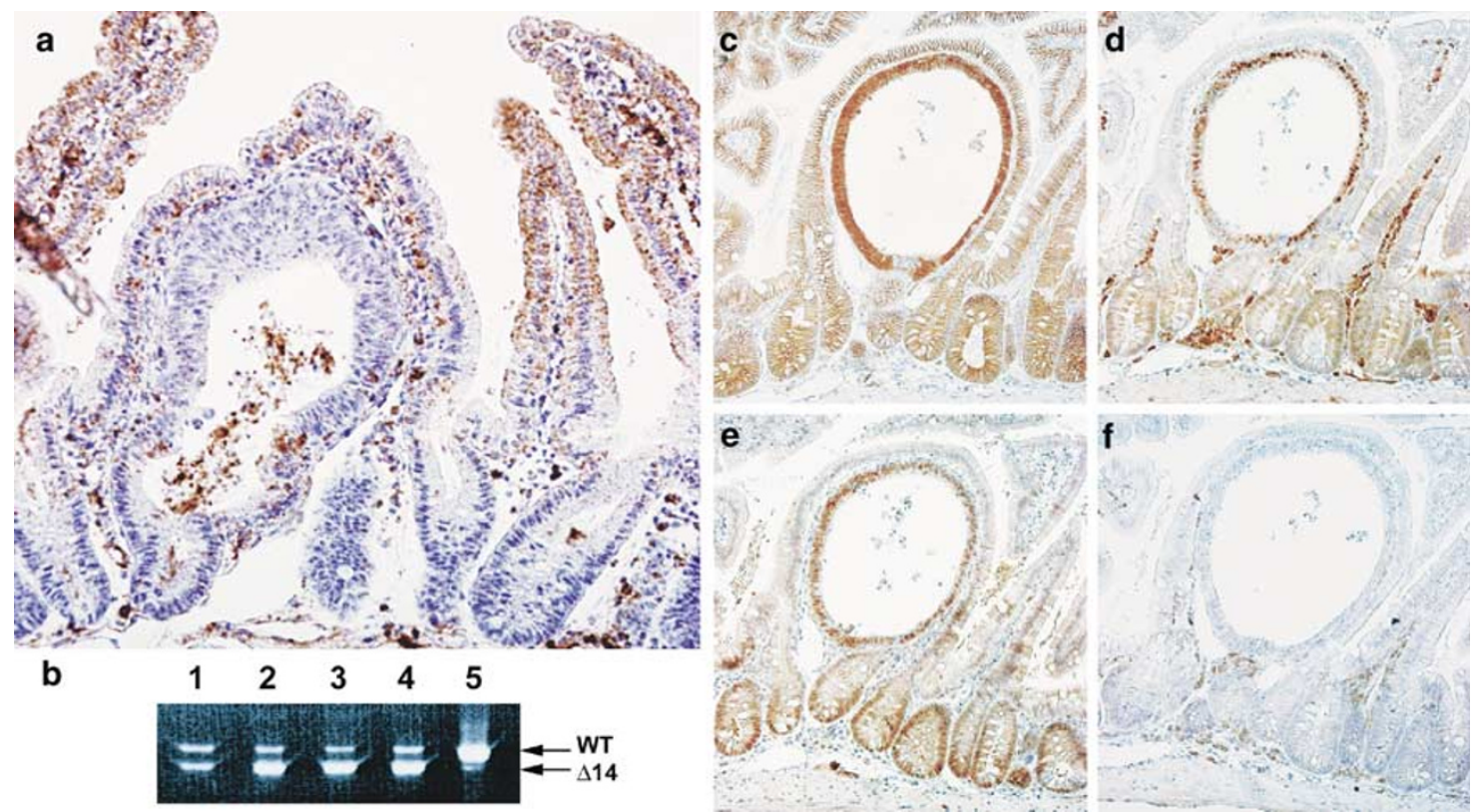

Figure 7 Molecular analysis of the early lesions of the small intestine of $A p c^{\Delta 14 /+}$ mice. (a) Immunostaining for Apc (magnification $\times 400$ ) in the normal epithelium. Villus enterocytes contain Apc in their cytosols with the concentration increasing to the tip of the villus. There was no staining in crypt cells. There is no Apc in the early lesion, while the surrounding normal epithelium is stained. Stromal cells and the necrotic contents of the dysplastic crypts show nonspecific staining, as do control sections without the primary antibody (not shown). (b) PCR analysis of genomic DNA isolated after microdissection of early dysplastic lesions (2-4), of normal adjacent epithelium (1), and the normal epithelium of a wild-type mouse (5). A $160 \mathrm{bp}$ product indicates $A p c$-targeted allele ( $\Delta 14$ ), while a $180 \mathrm{bp}$ product reveals the $A p c$ wild-type allele (WT). (c-f) Immunostaining of early lesions of the small intestine, in which the dysplastic crypt is surrounded by normal epithelium, magnification $\times 200$ : (c) $\beta$-catenin; (d) cyclin D1; (e) c-Myc; (f) glutamine synthetase.

The main difference between $A p c^{\mathrm{Min} /+}$ and $A p c^{\Delta 14 /+}$ mice is that the polyps are mainly in the colon of $A p c^{\Delta 14 /+}$ mice. The premature stop codon at AA580 results in the deletion of the Armadillo domains of the Apc protein (between AA435 and AA766) in these mice, while the protein truncated at codon 850 in $A p c^{\mathrm{Min} /+}$ mice contains intact Armadillo domains. These Armadillo domains were shown by two-hybrid systems to bind to a GTPexchange factor for Rho and Rac, named ASEF, ${ }^{26,27}$ to the B56 subunit of PP2A, ${ }^{28}$ and to the kinesin superfamily-associated protein 3 (KAP3). ${ }^{29}$ We do not yet know if the Armadillo domain in $A p c^{\mathrm{Min} /+}$ mice is responsible for the attenuation of the tumor production in the colon.

We also show that the intestinal microenvironment influences colon tumor formation. Differences in tumor development in the small intestine and colon have already been described. Ectopic grafts from $A p c^{\mathrm{Min} /+}$ fetal epithelia of either small or large intestine were used to show that colon tumors did not develop autonomously within the colon grafts, while small intestine tumors $\operatorname{did}^{30}$ Thus, this nonautonomous development of colon tumors in $A p c^{\mathrm{Min} /+}$ mice seemed to require factors in addition to the $A p c^{\mathrm{Min} /+}$ genotype. The microenvironmental factors acting on the severity of polyposis in $\mathrm{Apc}^{+/-}$ mice could be dietary and/or the intestinal flora, as reviewed in Corpet and Pierre. ${ }^{31}$ As $A p c^{\Delta 14 /+}$ mice kept in the two housing conditions were fed the same diet, the gut bacterial content is probably the critical factor responsible for the difference in phenotype, although we have not identified the microorganism involved. For example, two bacterial species known to contribute to colorectal polyposis: Helicobacter hepaticus and Citrobacter rodentium, ${ }^{32}$ could not be detected in $A p c^{\Delta 14 /+}$ mice raised in conventional housing. As gut commensal microorganisms have been shown to be able to contribute to colorectal carcinogenesis, ${ }^{32}$ it is therefore not excluded that subtle differences in the equilibrium of the gut microflora could be responsible for the shift in the colon of the $A p c^{\Delta 14 /+}$ mice polyposis, unless it should be attributable to an unidentified pathogenic microorganism.

Associated with the severe colon polyposis, we observe that $A p c^{\Delta 14 /+}$ develop rectal prolapses. Rectal prolapses develop also in $\mathrm{IL}-2^{-/-}$, IL-10 ${ }^{-/-}$, TGF $\beta 1^{-1-}$ and TCR $\beta^{-1-}$ mice, models of inflammatory bowel disease. ${ }^{16}$ Few of them subsequently develop colorectal cancers. ${ }^{33}$ Since no evidence for precancerous inflammatory lesions or for a preexisting IBD can be seen in our model, it is likely that the process of prolapse formation is different in the IBD mouse models than in the $A p c^{\Delta 14 /+}$ model. Similar to the $A p c^{\Delta 14 /+}$ model, other CRC mouse models, $A p c^{\mathrm{Min} /+} \mathrm{xIGF} 2$ and SMAD3 ${ }^{-/-}$mice, both developing CRC without a latent IBD, harbor rectal 
prolapses. ${ }^{34,35}$ A pathogenesis of IBD is not the primary cause of development of rectal prolapse in these three mouse models of CRC, even if a role of inflammation in colon carcinogenesis process need to be investigated.

Lastly, the $A p c^{\Delta 14 /+}$ model is suitable for use in the search for new relevant targets of $\beta$-catenin signalling that take part in the initation or progression of tumorigenesis. Early lesions, which are abundant in the small intestine, are a valuable tool for checking targets. This report shows that they contain no Apc, accumulate $\beta$-catenin, and overexpress cyclin D1 and c-Myc. Thus, we have confirmed that these are targets that respond rapidly to the activation of the $\beta$-catenin signalling pathway. Analysis of the early lesions also indicates that GS is not an early target of $\beta$-catenin signalling in the intestine; this was confirmed by the patchy overproduction of the protein in adenomas. Another target of $\beta$-catenin in the liver, LECT2, is also not overproduced in the polyps of $A p c^{\Delta 14 /+}$ mice. ${ }^{36}$ This apparent tissue-specific expression of the $\beta$-catenin target genes has been described previously, as the cyclin D1 and c-Myc genes are not upregulated in the liver of mice overproducing an oncogenic form of $\beta$-catenin. ${ }^{37}$ The details of the genetic program induced by $\beta$-catenin in vivo will be important for understanding the cell-specificity of the transformation induced by $\beta$-catenin. We believe that the $A p c^{\Delta 14 /+}$ model is an appropriate tool for studies designed to determine the processes involved in carcinogenesis in the colon.

\section{Acknowledgements}

We thank Pr Axel Kahn for his unfailing support, and all the members of our team for helpful discussions. We also thank the staff of the Institut Cochin and CDTA Orléans animal units for skilful animal care.

This work was supported in part by grants from Aventis France, the 'Association pour la Recherche contre le Cancer (ARC)' and the 'Ligue Contre le Cancer.'

\section{References}

1 Nishisho I, Nakamura Y, Miyoshi Y, et al. Mutations of chromosome 5q21 genes in FAP and colorectal cancer patients. Science 1991;253:665-669.

2 Kinzler KW, Nilbert MC, Su LK, et al. Identification of FAP locus genes from chromosome 5q21. Science 1991;253:661-665.

3 Kinzler KW, Vogelstein B. Lessons from hereditary colorectal cancer. Cell 1996;87:159-170.

4 Korinek V, Barker N, Morin PJ, et al. Constitutive transcriptional activation by a beta-catenin-Tcf complex in APC-/- colon carcinoma. Science 1997;275: 1784-1787.
5 Morin PJ, Sparks AB, Korinek V, et al. Activation of beta-catenin-Tcf signaling in colon cancer by mutations in beta-catenin or APC. Science 1997;275: 1787-1790.

6 Giles RH, van Es JH, Clevers H. Caught up in a Wnt storm: Wnt signaling in cancer. Biochim Biophys Acta 2003;1653:1-24.

7 Polakis P. Wnt signaling and cancer. Genes Dev 2000;14:1837-1851.

8 He TC, Sparks AB, Rago C, et al. Identification of cMYC as a target of the APC pathway. Science 1998;281: 1509-1512.

9 Tetsu O, McCormick F. Beta-catenin regulates expression of cyclin D1 in colon carcinoma cells. Nature 1999;398:422-426.

$10 \mathrm{Su} \mathrm{LK}$, Kinzler KW, Vogelstein B, et al. Multiple intestinal neoplasia caused by a mutation in the murine homolog of the APC gene. Science 1992;256: 668-670.

11 Oshima M, Oshima H, Kitagawa K, et al. Loss of Apc heterozygosity and abnormal tissue building in nascent intestinal polyps in mice carrying a truncated Apc gene. Proc Natl Acad Sci USA 1995;92:4482-4486.

12 Fodde R, Edelmann W, Yang K, et al. A targeted chaintermination mutation in the mouse Apc gene results in multiple intestinal tumors. Proc Natl Acad Sci USA 1994;91:8969-8973.

13 Sasai H, Masaki M, Wakitani K. Suppression of polypogenesis in a new mouse strain with a truncated Apc(Delta474) by a novel COX-2 inhibitor, JTE-522. Carcinogenesis 2000;21:953-958.

14 te Riele H, Maandag ER, Berns A. Highly efficient gene targeting in embryonic stem cells through homologous recombination with isogenic DNA constructs. Proc Natl Acad Sci USA 1992;89:5128-5132.

15 Leneuve P, Colnot S, Hamard G, et al. Cre-mediated germline mosaicism: a new transgenic mouse for the selective removal of residual markers from tri-lox conditional alleles. Nucleic Acids Res 2003;31:e21.

16 Boivin GP, Washington K, Yang K, et al. Pathology of mouse models of intestinal cancer: consensus report and recommendations. Gastroenterology 2003;124: $762-777$

17 Mombaerts P, Mizoguchi E, Grusby MJ, et al. Spontaneous development of inflammatory bowel disease in T cell receptor mutant mice. Cell 1993;75:274-282.

18 Sadlack B, Merz H, Schorle H, et al. Ulcerative colitislike disease in mice with a disrupted interleukin-2 gene. Cell 1993;75:253-261.

19 Berg DJ, Davidson N, Kuhn R, et al. Enterocolitis and colon cancer in interleukin-10-deficient mice are associated with aberrant cytokine production and CD4(+) TH1-like responses. J Clin Invest 1996;98: 1010-1020.

20 Cadoret A, Ovejero C, Terris B, et al. New targets of beta-catenin signaling in the liver are involved in the glutamine metabolism. Oncogene 2002;21: 8293-8301.

21 Hirose Y, Kuno T, Yamada Y, et al. Azoxymethaneinduced beta-catenin-accumulated crypts in colonic mucosa of rodents as an intermediate biomarker for colon carcinogenesis. Carcinogenesis 2003;24: 107-111.

22 Oshima H, Oshima M, Kobayashi M, et al. Morphological and molecular processes of polyp formation in Apc(delta716) knockout mice. Cancer Res 1997;57: 1644-1649. 
23 Batlle E, Henderson JT, Beghtel H, et al. Beta-catenin and TCF mediate cell positioning in the intestinal epithelium by controlling the expression of EphB/ ephrinB. Cell 2002;111:251-263.

24 Crabtree MD, Tomlinson IP, Hodgson SV, et al. Explaining variation in familial adenomatous polyposis: relationship between genotype and phenotype and evidence for modifier genes. Gut 2002;51:420-423.

25 Knudsen AL, Bisgaard ML, Bulow S. Attenuated familial adenomatous polyposis (AFAP): a review of the literature. Fam Cancer 2003;2:43-55.

26 Kawasaki Y, Sato R, Akiyama T. Mutated APC and Asef are involved in the migration of colorectal tumour cells. Nat Cell Biol 2003;5:211-215.

27 Kawasaki Y, Senda T, Ishidate T, et al. Asef, a link between the tumor suppressor APC and G-protein signaling. Science 2000;289:1194-1197.

28 Seeling JM, Miller JR, Gil R, et al. Regulation of betacatenin signaling by the B56 subunit of protein phosphatase 2A. Science 1999;283:2089-2091.

29 Jimbo T, Kawasaki Y, Koyama R, et al. Identification of a link between the tumour suppressor APC and the kinesin superfamily. Nat Cell Biol 2002;4:323-327.

30 Gould KA, Dove WF. Action of Min and Mom1 on neoplasia in ectopic intestinal grafts. Cell Growth Differ 1996;7:1361-1368.
31 Corpet DE, Pierre F. Point: From animal models to prevention of colon cancer. Systematic review of chemoprevention in min mice and choice of the model system. Cancer Epidemiol Biomarkers Prev 2003; 12:391-400.

32 Huycke MM, Gaskins HR. Commensal bacteria, redox stress, and colorectal cancer: mechanisms and models. Exp Biol Med (Maywood) 2004;229:586-597.

33 Itzkowitz SH, Yio X. Inflammation and cancer IV. Colorectal cancer in inflammatory bowel disease: the role of inflammation. Am J Physiol Gastrointest Liver Physiol 2004;287:G7-G17.

34 Hassan AB, Howell JA. Insulin-like growth factor II supply modifies growth of intestinal adenoma in Apc(Min/+) mice. Cancer Res 2000;60:1070-1076.

35 Zhu Y, Richardson JA, Parada LF, et al. Smad3 mutant mice develop metastatic colorectal cancer. Cell 1998;94:703-714.

36 Ovejero C, Cavard C, Perianin A, et al. Identification of the leukocyte cell-derived chemotaxin 2 as a direct target gene of beta-catenin in the liver. Hepatology 2004;40:167-176.

37 Cadoret A, Ovejero C, Saadi-Kheddouci S, et al. Hepatomegaly in transgenic mice expressing an oncogenic form of beta-catenin. Cancer Res 2001;61: 3245-3249. 